\title{
Fast and simple method with NPP fence measurements for source term estimation and its integration in JRODOS
}

\author{
J. Duran $^{1}$, T. Duranova ${ }^{1}$, J. Bohunova ${ }^{1}$, I. Kovalets ${ }^{2}$ and D. Trybushnyi ${ }^{3}$ \\ 1 VUJE, Inc., Okružná 5, 91864 Trnava, Slovakia. \\ ${ }^{2}$ Ukranian Centre for Environmental and Water Projects, prosp. Glushkova, 42, Kiev, Ukraine. \\ ${ }^{3}$ KIT - Karlsruhe Institute of Technology, Hermann-von-Helmholtz-Platz 1, 76344 Eggenstein-Leopoldshafen, Germany.
}

\begin{abstract}
A fast and simple method using Nuclear Power Plant fence measurements for source term estimation is presented in this work. The method is suitable for usage in a decision support system for off-site emergency management such as JRODOS. The article provides short introduction to basic principles and model application, input data, methodology, uncertainty handling, outputs and integration of software tool in JRODOS.
\end{abstract}

Keywords: source term / fence measurements / nuclear emergency / JRODOS

\section{Introduction}

Given the difficulties of estimating the emissions of radionuclides ("source term") for an ongoing or recent accidental release, as experienced both in the Chernobyl and Fukushima accidents, and at the same time the high importance of the source term for the subsequent prognosis (and associated uncertainties) of consequences, the task on source term estimation has become part of different international projects. The existing high-level expertise within the PREPARE Project consortium in computational methods for source term estimation combining measurements and dispersion modelling formed the basis for developing and integrating in Decision Support Systems (DSSs) for nuclear emergencies operational modules assessing the "source term" using measurements such as gamma dose rate in air.

The new development has used as starting point an existing method that has been previously tested and used for estimating atmospheric release rates of nuclides. The basic method is associated with operational models of DSS RTRAC (RealTime Accident Release Consequences) developed by VUJE and implemented and used at the Emergency Response Centre of the Nuclear Regulatory Authority of Slovak Republic and at the Slovak and Czech Nuclear Power Plants (NPPs).

In the PREPARE project a simple and fast tool has been established that can estimate the source term using gamma dose rate measurements in the near vicinity of NPP - "at the fence". It should be mentioned that in frame of the same project more advanced and complex source inversion method has been also developed which is capable of using measurements at wide range of distances from the NPP (Kovalets et al., 2016).

The tool presented in this article recognizes the occurrence of a release and estimates the source term using pre-calculated normalized dose rates (i.e., for unit activities of representative nuclides) for all detector points, different release heights, and given meteorological situations. The estimated source term is provided to the DSSs for dispersion calculations and consequence assessment.

\section{Methodology}

The methodology, conceptual design and computational methods are thoroughly presented and discussed by Duran et al. (2013) and Duran and Duranova (2014). The module for simple and fast estimate of source term using gamma dose rate measurements at the fence of the NPP (SIM-S) is activated upon new data arrival.

Based on the analyses of current data and data from the previous time step the module defines:

- how many detectors are affected by the release;

- which detectors have been affected for the current time step (detector identification, its coordinates);

- which detectors show error or failure of measurement (too low or zero value or abnormally high value exceeding the detector sensitivity).

Preconditions for the measurements analyses are the following:

- the location of affected detectors should correspond to the wind direction in the current time step of measurement;

- affected detectors should be next to each other;

- the measured value of the affected detector should be greater than the background (if the detector was not affected in the previous time step), or greater than the measurement range value of the detector if the detector was affected in some previous time of measurements.

Estimate of source term (ST) is done for each 10 min release. It is supposed that gamma dose rate data are available from 4 measurement points at maximum for each time step. The module 
Table 1. Radionuclide MELCORE groups and determined radionuclide representative.

\begin{tabular}{|lll}
\hline & Representative radionuclide MELCOR groups & Representative element for MELCOR group \\
\hline 1 & Noble Gasses & $\mathrm{Xe}$ \\
\hline 2 & Alkali Metals & $\mathrm{Cs}$ \\
\hline 3 & Alkaline Earths & $\mathrm{Ba}$ \\
\hline 4 & Halogens & $\mathrm{I}$ \\
\hline 5 & Chalcogens & $\mathrm{Te}$ \\
\hline 6 & Platinoids & $\mathrm{Ru}$ \\
\hline 7 & Early Transition Elements & $\mathrm{Mo}$ \\
8 & Tetravalents & $\mathrm{Ce}$ \\
\hline 9 & Trivalents & $\mathrm{La}$ \\
10 & More Volatile Main Group & $\mathrm{Cd}$ \\
\hline
\end{tabular}

Table 2. Order of calculated released activities of the representative radionuclides for $N$ measurements.

\begin{tabular}{|c|c|c|c|c|c|c|c|c|c|c|}
\hline$N=1$ & ${ }^{133} \mathrm{Xe}$ & & & & & & & & & \\
\hline$N=2$ & ${ }^{133} \mathrm{Xe}$ & ${ }^{136} \mathrm{Cs}$ & & & & & & & & \\
\hline$N=3$ & ${ }^{133} \mathrm{Xe}$ & ${ }^{136} \mathrm{Cs}$ & ${ }^{140} \mathrm{Ba}$ & & & & & & & \\
\hline$N=4$ & ${ }^{133} \mathrm{Xe}$ & ${ }^{136} \mathrm{Cs}$ & ${ }^{140} \mathrm{Ba}$ & ${ }^{131} \mathrm{I}$ & & & & & & \\
\hline \multicolumn{11}{|l|}{$\ldots$} \\
\hline$N=10$ & ${ }^{133} \mathrm{Xe}$ & ${ }^{136} \mathrm{Cs}$ & ${ }^{140} \mathrm{Ba}$ & ${ }^{131} \mathrm{I}$ & ${ }^{132} \mathrm{Te}$ & ${ }^{103} \mathrm{Ru}$ & ${ }^{99} \mathrm{Mo}$ & ${ }^{143} \mathrm{Ce}$ & ${ }^{140} \mathrm{La}$ & ${ }^{127} \mathrm{Sb}$ \\
\hline
\end{tabular}

uses a simple method for solving $N$ linear algebraic equations with $N$ unknown parameters ( $N$ measurements, $N$ nuclides activities). Normalized dose rates (from cloud and deposit exposure) are pre-calculated for different parameters:

- release height (10 classes of height-maximal height $200 \mathrm{~m})$;

- initial width (radius) of cloud (10 classes of width - influence of reactor building cavity);

- category of stability class (6 classes);

- wind speed (10 classes);

- intensity of precipitation (10 classes).

Dose rates are pre-calculated for the 10 representative nuclides given in Table 1 . The order of calculated released activities of representative radionuclides, depending on the number of available measurements is presented in Table 2.

The methodology takes into account information about uncertainties of dose rate measurements and threshold of measurements (minimal measured value).

As a result we have:

- released activities for $N$ nuclides $\left(Q_{i}\right)$, which give the dose rates closest to real measurements (least squares of differences between measurements and calculated values);

- ranges of activities $\left(\Delta Q_{i}\right)$ which give results in the range of uncertainties of dose rate measurements.
The quality of results depends on the number of measurements taken into consideration - the more measurements the less uncertainty of the estimated source term.

\section{Results of calculations}

The newly developed and integrated in JRODOS source inversion module SIM-S has been tested using artificially generated measurements calculated by JRODOS. The measurement stations were registered in JRODOS database. Gamma dose rates (GDR) were calculated at those points using JRODOS LSMC (with ATSTEP model) using the following meteorological scenario: wind speed $2.5 \mathrm{~m} \mathrm{~s}^{-1}$, stability $D$, initial wind direction $260 \mathrm{deg}$, turning cyclonically by $15 \mathrm{deg}$ every $0.5 \mathrm{~h}$. The source term used in calculations was in the range of $1 \times 10^{17} \mathrm{~Bq}$ for the noble gases and $1 \times 10^{13} \mathrm{~Bq}$ for other radionuclide groups. The obtained GDR values at detector points were input as artificial measurements in JRODOS database and then used in SIM-S run. As it was previously described SIM-S uses measurements of up to 4 stations at which maximum concentrations at a given time step are observed. The source term calculated by SIM-S with the 10-min time step was then used by LSMC to calculate spatial distribution of total effective gamma dose rate from all nuclides. The corresponding spatial distributions of GDR 


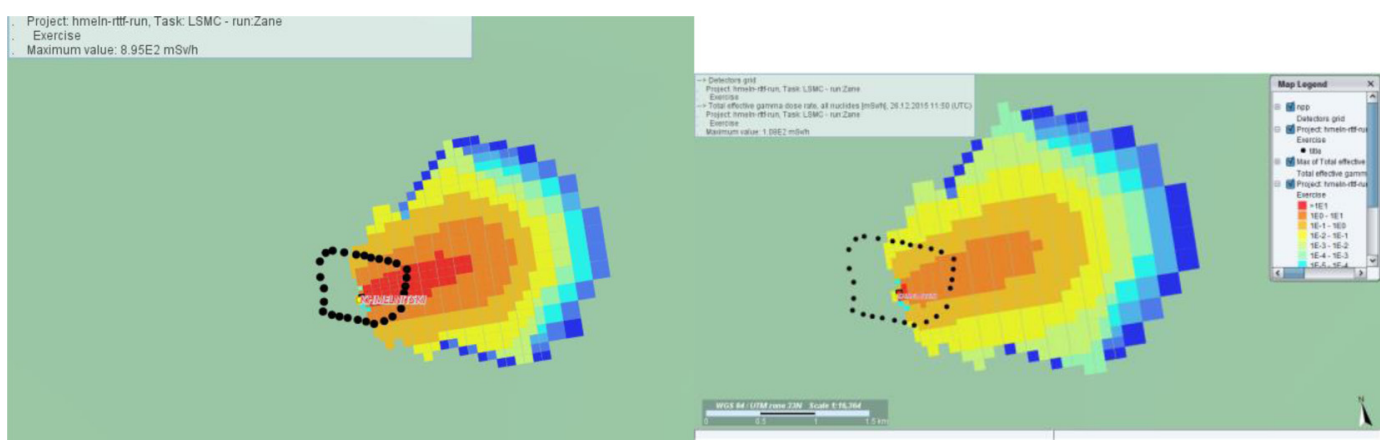

Figure 1. Calculated field of gamma dose rate with 'true' source term (left) and with adjusted source term (right).

obtained with true and estimated source terms are presented in Figure 1. It can be seen that the algorithm is able to produce useful estimation of the source term (taking into account that prior information was not used at all); however, the obtained GDR are underestimated, e.g., maximum values of GDR differed by a factor of 8.9 .

\section{Conclusions}

A software tool (SIM-S) for simple and fast estimate of source term using gamma dose rate measurements at the NPP fence has been developed and integrated in JRODOS. The testing of the algorithm demonstrated that:

- the algorithm produced underestimated values of the released activity as manifested by the maximum value of calculated GDR;

- despite the above underestimation, the source term estimation produced by SIM-S was useful taking into account the fact that not any prior information about the released activities was used in source inversion procedure.
More testing of the algorithm is planned for the future to improve its stability under quickly changing meteorology. In addition exact correspondence between nuclide groups used in simple source inversion method and JRODOS nuclide groups has to be established.

Acknowledgments. The research leading to these results has received funding from the European Atomic Energy Community Seventh Framework Programme FP7/2012-2013 under grant agreement 323287.

\section{References}

Duran J., Duranova T. (2014) Conceptual design of the software tool for simple and fast estimate of source term using gamma dose rate measurements at the fence, PREPARE(WP4)-(14)-02, March 2014.

Duran J., Bohunova J., Duranova T. (2013) Methodology and computational methods for simple estimate of source term using gamma dose rate measurements at the fence, PREPARE(WP4)(13)-03, November 2013.

Kovalets I., Andronopoulos S., Hofman R., Seibert P., Ievdin I. (2016) Description of software module for source term estimation integrated in DSS RODOS, PREPARE(WP4)-(16)-04.

Cite this article as: J. Duran, T. Duranova, J. Bohunova, I. Kovalets, D. Trybushnyi. Fast and simple method with NPP fence measurements for source term estimation and its integration in JRODOS. Radioprotection 51(HS2), S117-S119 (2016). 